\title{
As aparências não enganam: as representações sociais de qualidade suscitadas pelos prédios escolares
}

Luís Carlos Sales

Universidade Federal do Piauí, Mestrado em Educação

Guiomar de Oliveira Passos

Universidade Federal do Piauí, Mestrado em Políticas Públicas

\section{Introdução}

O uso recorrente de uma palavra, assim como o excesso de visibilidade de algo, não a torna, por si só, facilmente compreendida ou aceita, pois a compreensão de uma palavra ou de um fato não depende necessariamente da evidência de ambos. Trata-se de uma lição acaciana de razoável valor. Qualidade - do ensino, da escola, da educação - é um bom exemplo. O que é um ensino de qualidade, uma escola de qualidade, uma educação de qualidade? Ainda que todos tenham uma noção e de algum modo saibam a que se referem quando desejam, propõem ou têm como objetivo um ensino de qualidade, uma escola de qualidade e uma educação de qualidade são idéias por demais abstratas, seus sentidos são polivalentes. É algo que ninguém pergunta o que é; sabe-se do que se trata, mas que não se sabe explicar. Diante de um questionamento sobre o que é qualidade, não se sabe o que dizer.

A definição de qualidade tem sido uma das dificuldades na fixação do custo do padrão mínimo de qualidade do ensino estabelecido pelo Fundo de Desenvolvimento do Ensino Fundamental (FUNDEF) para os formuladores e gestores da política, para os órgãos de pesquisa e até mesmo para entidades da sociedade civil. Uma das explicações para o governo federal continuar fixando, até o momento, o valor mínimo anual por aluno sem levar em conta a variável qualidade do ensino pode ser a dificuldade para definir uma expressão monetária do custo-aluno-qualidade. ${ }^{1}$

A ausência de uma definição de qualidade, portanto, impede o estabelecimento de parâmetros norteadores para alocação de recursos. A polissemia do vocábulo "qualidade" favorece não só alguns reducionismos (como faz o Plano Nacional de Educação, lei n. 10.172/01, ao deter-se na infra-estrutura ou mesmo nas avaliações da política de educação, ao enfocar apenas os custos) como também alimenta as mais diversas expectativas e algumas ilusões.

Esse tema tem inquietado elaboradores de políticas e pesquisadores da área de educação, constituindo

\footnotetext{
${ }^{1}$ A data-limite para o Estado brasileiro fixar o valor do custo-
} aluno/ano de modo que se garanta um valor que correspondesse ao custo do padrão mínimo de qualidade do ensino era 12 de setembro de 2001, decorridos cinco anos da implantação do FUNDEF. 
ponto destacado de suas agendas. ${ }^{2}$ Pesquisa realizada por Sales (2000, p. 261) constatou a influência exercida pelo prédio escolar no julgamento da sociedade sobre a qualidade de ensino de uma escola e evidenciou os critérios utilizados nas apreciações dos sujeitos pesquisados. Este artigo analisa tais apreciações, identificando os significados de qualidade do ensino subjacentes a elas. A idéia é que nessas apreciações se encontram princípios geradores de tomadas de posição, de atitudes e de práticas, posto que são ações sociais e, como tais, possuem um sentido, "orienta[m]-se pelo comportamento de outros", nas palavras de Weber (1995, p. 415), e, por conseguinte, oferecem elementos para um conceito de ensino de qualidade.

Os sentidos que se manifestam em ações concretas e envolvem os motivos apontados como fundamentos de uma ação - em síntese, aqueles presentes nos fins estabelecidos em uma ação - constituem fontes de representações coletivas e sociais. Desse modo, são "produto de uma imensa cooperação que se estende não apenas no espaço, mas no tempo" (Durkheim, 1978, p. 216) e também "uma modalidade específica de conhecimento que tem por função a elaboração de comportamentos e a comunicação entre indivíduos no quadro da vida cotidiana" (Sá, 1995, p. 23).

Neste artigo, investigam-se as representações sociais presentes nas apreciações das escolas feitas por pais de estudantes do ensino fundamental e médio a partir dos prédios escolares. Compreende-se que essas apreciações servem de referência para suas condutas, produzindo e determinando comportamentos, uma vez que as representações sociais "[...] definem simultaneamente a natureza dos estímulos que nos cercam e nos provocam e o significado das respostas a darlhes" (Moscovici, 1978, p. 26). Parte-se da seguinte pergunta: que representações sociais de qualidade do ensino estão presentes nas apreciações das escolas que os pais de estudantes do ensino fundamental e médio

2 No XVII Encontro de Pesquisa Educacional do Norte e Nordeste (EPENN), realizado em Belém (PA), em junho de 2005, por exemplo, foram apresentadas sete pesquisas sobre qualidade (EPENN, 2005, p. 135-186). fizeram a partir das fachadas dos prédios escolares? Foram utilizadas as entrevistas feitas para a pesquisa sobre o "o valor simbólico do prédio escolar", de Sales (2000), ${ }^{3}$ destacando os critérios de julgamento envolvidos na classificação das escolas, ou seja, os princípios norteadores da ação.

O texto está estruturado em três partes. $\mathrm{Na}$ primeira, são expostas as apreciações das escolas a partir dos prédios escolares, tendo por base as idéias recorrentes entre os entrevistados nesse julgamento. Em seguida, identificam-se os elementos recorrentes nas apreciações, listando aqueles que constituem o sentido de qualidade para os entrevistados e são significativos para a construção de um conceito de qualidade. Finalmente, analisam-se esses elementos, buscando o que está subjacente, ou antes, os princípios geradores das apreciações.

\section{Impressões da aparência}

Conforme observou Sales (2000, p. 88), “[...] o critério nível de ensino da escola era uma espécie de variável dependente, ou seja, ele sempre aparecia na maioria das entrevistas atrelado a outros critérios de classificação [...]"; por conseguinte, como um aspecto decorrente de outros fatores, uma conseqüência. A partir dessa constatação, a reunião das apreciações, conforme cada fator ou "variável independente", torna os princípios geradores ou os critérios de julgamento subjacentes a essas apreciações mais evidentes, fornecendo os elementos para a apreensão das representações sociais de qualidade do ensino.

Um primeiro fator destacado na apreciação das fotografias das escolas, ao qual está vinculada a qualidade do ensino, é a clientela atendida. Aqui, para muito além de uma compreensão republicana de educação para todos, expõe-se uma realidade social

\footnotetext{
${ }^{3}$ Foram entrevistados 240 sujeitos com filhos ou netos
} regularmente matriculados em escolas de Teresina e de Natal, tendo como estímulo visual um conjunto de 20 fotografias de prédios escolares selecionados a partir de consulta a historiadores e educadores das duas cidades. 
em que existem "escolas de rico ou de alta classe" e "escolas de pobre".

Escolas... de alto padrão, pelas fotografias nós... nós vemos que são escolas... da classe alta. (11T, m, 47, ES, nse-m)

Porque é um colégio bom, a gente já tem visto pessoas formadas por ele. Até o Átila Lira já foi formado nesse colégio. A minha filha já estudou lá. (32T, f, 50, EF, nse-b)

Escolas de classe baixa, nós vemos aqui... é... casas paupérrimas... (11T, m, 47, ES, nse-m)

A designação "escola de rico" ou "escola de pobre" expressa a situação socioeconômica dos alunos e a compreensão do que na teoria se convencionou chamar "efeito-clientela", ou seja, a influência das características sociais, econômicas e culturais da família e do ambiente quotidiano, bem como do conhecimento trazido pelos alunos ao entrar na escola, no desempenho escolar:

É porque me parecem escolas ricas, né? E uma vez ricas, certamente dão acesso a filhos de ricos, não é? E filhos de ricos normalmente são bem nutridos... lhes causando melhor discernimento. (24T, m, 41, EM, nse-m)

Tá mostrando que aqui é escola de pobre... Aquele pobre mesmo que vai pro colégio de pé descalço... Este outro grupo tá mostrando que é aluno de bairro, lá da periferia; que o aluno vai com a calça de farda, mas não vai com a camisa; se vai com a camisa, não vai com a calça de farda. $\mathrm{O}$ aluno aqui ainda vai de chinelo, porque a estrutura física tá mostrando. (94T, m, 43, EM, nse-m)

Pelas condições da escola, né? Quase não tem carteira. Os alunos não têm... às vezes têm merenda, às vezes não têm. $\mathrm{E}$ às vezes a criança sai sem tomar nem café, né? Muitas escolas

${ }^{4}$ A codificação ou legenda adotada para identificar os sujeitos seguirá este modelo: $11 \mathrm{~T}=$ sujeito 11 de Teresina, $\mathrm{m}=$ masculino, 47 = idade do sujeito, ES = ensino supletivo, nse-m = nível socioeconômico médio. Os grifos são nossos. públicas assim, às vezes as crianças não tomam nem café de manhã e vai para a escola estudar. Aí, como é que eu peço a pessoa para assimilar as coisas de barriga vazia, aí não tem nem condição. (15T, f, 32, EM, nse-b)

Contudo, há também a percepção de que o processo educacional envolve uma teia complexa de fatores da qual participam, ao lado das características sociais, econômicas e culturais da família e das habilidades do aluno, os fatores escolares, ou seja, elementos intra-escolares, como as condições de trabalho e qualificação dos professores e condições físicas adequadas, o chamado "efeito-escola", como tratam Ferrão e Fernandes (2003):

[...] colégio de gente rica, como é que a gente diz... colégio assim de... colégio que tem também mais tradição, que tem... tem melhores condições de pagar os professores. (8T, f, 50, EM, nse-m)

\section{[...] aí só estuda filho de barão, de gente que tem condição} mesmo; pobre não tem condição de maneira nenhuma, vontade tem, porque é um colégio de capacidade, bem elevado em termo de ensino, só professores bons, é isso aí... Eu... a gente queria é... o futuro pro filho da gente um colégio desses aí, mas às vezes, vem a situação financeira que fala mais alto. (33T, f, 23, EF, nse-b)

Primeiro pela própria situação geográfica: Aqui estou vendo que é uma palafita e isso é o quê? O fluxo e o refluxo de água da maré! Com certeza isso aqui tem uma podridão aqui embaixo, horrível. A sala não é adequada, e os professores com certeza não são adequados e isso significa um padrão baixíssimo de aprendizagem. (117T, m, 45, ES, nse-m)

Como em estudos recentes (Ferrão \& Fernandes, 2003), os entrevistados percebem que, na junção das condições socioeconômicas e culturais da família com as condições escolares, se obtém como resultado a reprodução de desigualdades sociais também no que se refere à qualidade do ensino, sintetizada pela máxima "escola de rico tem qualidade, escola de pobre não tem qualidade, o conhecimento é precário": 
Isso são escolas particulares e da alta classe social porque [...] a classe social alta, ela evidencia não o ser, mas o ter. Ela acha... muitos... muitos pais - gente que tem recursos suficientes - acham que [...] a educação vale o quanto paga. Então, quem paga... quem paga tem boa escola, quem não paga... vai para a escola pública, quem vai para escola menos... quem tem menos despesas. (69T, $\mathrm{m}, 53$, ES, nse-m)

É uma escola de favela, acho que o conhecimento é precário; [a outra é] uma escola rural. Eu acho que essas deixam a desejar a qualidade do ensino. (42T, f, 25, ES, nse-m)

Um segundo fator do qual depende a qualidade do ensino é o vínculo institucional. Como observado por Sales (2000, p. 89), a classificação entre escola pública e escola particular constituiu o principal eixo de diferenciação das escolas. Ser escola pública ou particular e, entre essas, vincular-se ou pelo menos possuir sinais de pertencimento a alguma organização religiosa, principalmente católica, diz muito sobre a clientela atendida, a qualificação e remuneração dos professores, a aprendizagem dos alunos e a qualidade do ensino:

Porque, com certeza, são escolas é... públicas, a 7 assemelha-se às escolas públicas estaduais - os CAICs; a 3, às escolas públicas municipais que têm um ensino não de... não de tão bom nível, mas um ensino voltado é... principalmente pra as classes menos privilegiadas e a... a cursos profi [...] profissionalizantes. (41T, n, 26, ES, nse-m)

Porque uma a gente vê que não tem nem condição mesmo da gente querer colocar o filho da gente; já tem a 10 que já foi uma escola de nome e deveria hoje ser uma escola, continuar uma escola maravilhosa; pelo fato de ser escola do governo, que o governo mantém, mas, infelizmente hoje o quadro é... o quadro de escolaridade é tão fraco, né? No sentido de ser escola pública que eu não gostaria de colocar meus filhos em nenhuma escola dessas. (56T, f, 28, EM, nse-m)

São escolas que pela imensa pobreza se pode imaginar e as demais, no caso, [...] por tratar pela aparência de escolas do Estado e se sabe que são escolas mal tratadas pelos órgãos governamentais. (24T, m, 41, EM, nse-b)

Porque são escolas... as escolas públicas estão em decadência, né? Não... os professores não... não são qualificados e a própria estrutura da escola, né? Não oferece boas condições. (78T, m, 34, ES, nse-m)

Porque são escolas particulares onde os professores são bem pagos e se esforçam mais para ensinar os alunos. (41T, n, 26, ES, nse-m)

Porque são escolas (particulares) que com certeza têm bons professores, né? E que iam ajudar melhor o meu filho e pelo menos o meu esforço não ia ser em vão, né? Porque é lógico que eu quero o melhor, não vou botar meu filho numa escola pública que não dá condições, porque é a realidade infelizmente; porque se desse, meu filho estaria numa escola pública, mas como não dá... (98N, f, 30, EM, nse-b)

Porque se trata de uma escola particular, né? E onde os professores certamente recebem seus salários em dia, não é? Também com isso eles são motivados, exatamente pelo fato de receber sempre em dia; certamente bem mais preparados, então faz com que os alunos ganhem melhor conhecimento. (24T, m, 41, EM, nse-b)

Porque a gente já conhece e sabe que tem um... um ensino tradicional, né? essa também, [...], é uma escola particular, também eu acho que tem um bom ensino, e essas outras, que não é daqui de Teresina, eu acho que pela estrutura dá pra ver mais ou menos que tem um bom ensino, $\mathrm{a} \mathrm{n}^{\circ} 2 \mathrm{e}$ a ${ }^{\circ} 6$. (42T, f, 25, ES, nse-m)

Porque são da re... são particular e são colégio mais elevado. (47T, f, 40, EF, nse-b)

São escolas particulares com grandes prédios, grandes fachadas que demonstra melhoria na educação. (60T, m, 46, EM, nse-m)

São colégios particulares e tradicionais. (3T, f, 38, ES, nse-m) 
O vínculo com uma organização religiosa é um item à parte. Mais que o caráter privado do estabelecimento, é indicativo de que o ensino ali ministrado não apenas instrui como também forma:

Porque eu sei que é um bom colégio... é religioso... Vamos dizer que lá professoras e tudo são freiras, né? (4N, m, 37, ES, nse-m)

Eu acho que pela própria proposta inicial dos colégios [...] né? eles... eles têm aquela história do... do ensino é... preocupado também com a... com a... aliado a... a formação, né?, humanística também das pessoas e tal, são colégios religiosos, dirigidos por padre ou por freira e que talvez por conta disso tenha assim essa receptividade. Acredito que talvez por conta disso também, né? (78T, m, 34, ES, nse-m)

Nesses colégios, analisam os entrevistados, a administração e a disciplina são rígidas, o ensino é exigente:

É que esse grupo aqui me parece ser uma escola mais dirigida, assim, por pessoas religiosas, né? Parece ter uma diretoria mais controlada. (55N, m, 48, EF, nse-b)

Por serem escolas de... de... Primeiro porque são escolas envolvidas é... com Igreja, escola envolvida com... com... São muito rígidas; um ensino mais puxado que exige mais do aluno. (56T, f, 28, EM, nse-m)

Porque é colégio de padre... e padre é mais disciplinado... (98T, m, 35, ES, nse-b)

Aqui, a imagem esboçada pelos entrevistados muito se assemelha à traçada por Ruth Rocha (1986) em "Quando a escola é de vidro": a escola em que cada criança ficava dentro de um vidro cujo tamanho dependia da série em que cada um estudava. Isto é, a escola valorizada pelos entrevistados é a que impõe severos limites aos movimentos, à criatividade e a todas as formas de expressão, ou seja, que coloca cada um dentro de um determinado modelo, preferencialmente, cristão.
$\mathrm{Na}$ visão dos entrevistados, essas escolas são ricas, seus professores são mais bem remunerados, oferecem um leque maior de opções de atividades; em síntese, é uma escola da minoria e oferece o que é valorizado no momento pelo grupo ao qual pertence o aluno, de que é exemplo a informática:

Por aparentarem ser escolas religiosas, de uma certa riqueza também. (24N, m, 41, EF, nse-b)

Eu acredito que a maioria das pessoas pensa que a escola particular que tem caráter religioso, que tem melhor orçamento, melhor condição financeira, o aluno aprende mais. Embora isto não seja regra... (67T, m, 35, ES, nse-m)

Porque eu acho que [...] deve ser uma escola particular, não conheço, mas que se for escola particular, então se deve trabalhar com informática. (13N, m, 37, EM, nse-b)

Além desses elementos, a valorização da escola particular, laica ou religiosa, ainda denota o entendimento de que o pagamento pelo produto não apenas o torna de melhor qualidade, como também objeto de interesse.

Porque uma vez que o pai está pagando, ele (o aluno) se interessa para ser aprovado. (85T, m, 39, ES, nse-m)

Porque eu acho que são melhores, apesar de tudo são melhores, tá pagando, entendeu? Infelizmente hoje em dia num tem mais condições da gente formar um filho no estado. Em nosso tempo, meu marido foi formado no estado, mas hoje em dia... (118N, f, 40, EM, nse-m)

Eu vejo que o aluno aprende menos na escola pública, mas não é por causa da escola, não é a razão da escola, é por causa da irresponsabilidade dos dirigentes, por exemplo, do professor, do governador do estado que não pagam bem os professor, não é isso?

E eles começam se acomodar, ficam zangado, não vão às aulas, os alunos voltam, não assiste... passam semana sem ter aula, então, não tem condição de aprender. (55T, f, 57, EF, nse-b) 
Porque eu acho que nós achamos que a escola pública tá muito desvalorizada e tá muito desacreditada, então nós acreditamos que quem tem filhos, quem quer que um filho tenha um estudo melhor, nós acreditamos que a escola particular dá um melhor ensino. (19T, f, 42, EM, nse-m)

A remuneração do trabalho, pagar ou ser pago para fazê-lo, constitui, na teoria econômica clássica, parte do "homem econômico"; é um dos seus traços característicos, ou seja, da natureza do homem. Isso, como observou Polanyi (2000, p. 63), é típico daqueles que vivem nas sociedades capitalistas, em que a satisfação das necessidades passa necessariamente por transações comerciais e a força de trabalho se tornou uma mercadoria.

Outro fator que os entrevistados vincularam à qualidade do ensino foi a tradição, o que denota preocupação com experiência (alguém que sabe fazer), permanência (já faz há algum tempo), resultados auferidos (aprovação no vestibular, por exemplo), ao mesmo tempo em que significa garantia de rigidez, rigor disciplinar, ensino exigente. Contudo, o julgamento da escola segundo esse fator depende do seu vínculo institucional; para uma escola particular, ser tradicional é positivo:

São escolas tradicionais que a administração é, digamos, religiosa e que tentam, por conta da tradição, dar um ensino de qualidade durante a existência da escola. (76T, m, 30, ES, nse-b)

Porque é uma escola tradicional e religiosa, tem bons professores responsáveis, os alunos são muito cobrados em termos de estudo, oferece conforto e é bem localizada. (110T, f, 67, ES, nse-m)

São escolas antigas, são tradicionais. A gente vê pela arquitetura da escola. (115T, m, 41, ES, nse-m)

Porque são escolas de nome, escolas tradicionais que dão muita aprovação no vestibular, e a gente pensa no futuro do aluno. (110T, f, 67, ES, nse-m)
Porque pela característica eu vejo que são escolas é... vamos dizer assim de um... um... uma aparência um pouco antiga, que tem... que pela... pelo que eu vejo deve ter alguma influência de escolas religiosas. $(83 \mathrm{~N}, \mathrm{~m}, 34$, ES, nse-b)

Devido ser uns colégios bons, tradicionais, de bom ensino, vários alunos já têm passado no vestibular e é de ótima qualidade de ensino. (64T, f, 29, EM, nse-m)

A escola [...] é de tradição, escola rígida, uma escola que dá conforto também ao aluno... (38T, f, 23, EM, nse-b)

A tradição dispensa a propaganda; a ação exercida e os resultados alcançados encarregam-se de tornar uma escola tradicional conhecida. A publicidade que confere reconhecimento é mais aquela calcada nos resultados, feita mais pelos usuários do que pelos meios de comunicação de massa.

Porque é... uma tradição, se conhece a qualidade do ensino dessas duas escolas, não se vê propagandas, entendeu? não se vê propagandas de aprovados em vestibulares é realmente pela qualidade do ensino... (105T, m, 54, ES, nse-b)

Porque esses colégios, a maior parte nem fazem propaganda. Não divulgam nada e todos são cheios e lotados. Alguns fazem até seleção. (96T, m, 46, ES, nse-m)

Para as escolas públicas, contudo, a tradição é apenas mais um elemento para realçar sua decadência ou um parâmetro para separar o tempo de glória, um passado não tão longínquo, e o tempo presente:

Porque eu acredito que são as mais tradicionais... pelo menos pelo que eu tô divisando aqui, né? Estou identificando pelo nome, né? Aqui é a Escola Técnica, não tem nome, mas tem visual... O Atheneu, estabelecimento conceituado antigamente. E hoje... já não tem o mesmo conceito de outrora [...]. E o colégio Marista, o Santo Antônio, muito tradicional... (49N, m, 58, EM, nse-m) 
Porque essas escolas, a gente vê que elas são muito antiga, né? Umas escolas assim bem... então, antigamente, com certeza o ensinamento era melhor e os alunos dessas escolas, com certeza são bons. (16T, f, 31, EM, nse-b)

Há um estigma, como o observado por Sales (2000, p. 246), que impede que a tradição seja uma referência de qualidade do ensino quando se trata de escola pública, daí redundarem em fracasso as tentativas de dirigentes educacionais de "voltar ao passado", reacendendo símbolos como fardamento, fachada do prédio, normas disciplinares, entre outros.

Outro fator influente na qualidade de ensino, conforme os entrevistados, é a estrutura física. Elementos como conforto, salas amplas, espaços pedagógicos, laboratórios, áreas de lazer e suntuosidade não apenas constituem parte de um ensino de qualidade como também denotam outros indicadores dessa qualidade: professores bem pagos, formação humanista, modernidade:

Aqui são escolas reles, quer dizer, não têm nem estrutura de escola, são inapropriadas sobre qualquer aspecto, não é? E é de escolas públicas e das piores possíveis. (7T, m, 35, ES, nse-m)

Por ser escola que não apresenta o mínimo de dignidade a pessoa humana, porque aqui não... aparentemente, não tem nada; não tem nem espaço pruma pessoa sentar... não tem higiene, não tem um mínimo de motivação pruma criança ficar numa escola dessa. (81T, m, 26, ES, nse-b)

Porque são uns prédios fracos, sem estrutura, e acredito que os professores também são da mesma maneira. (110T, f, 67, ES, nse-m)

Pelo fato de elas terem o mesmo padrão é... são escolas simples de... de níveis inferiores e que não oferece é... um bom ensinamento, não têm condições de oferecer é... um bom ensinamento para os alunos. (68T, m, 37, ES, nse-m)

Porque aparentemente o... o próprio prédio, a própria instalação demonstra que ela não tem... se a instalação não é boa também eu acredito que o corpo docente também não deva ser bom. (4T, m, 37, ES, nse-b)

Exatamente essas aqui, [...], são as piores. Exatamente porque não têm estrutura física e naturalmente os professores que trabalham nessas escolas não têm qualificação devida... (7T, f, 35, ES, nse-m)

Apesar de eu não conhecer o colégio, mas a própria estrutura física do colégio demonstra que é um colégio de alto nível. (60T, m, 46, EM, nse-m)

Porque o aspecto dela pela construção, até pela quantidade de aparelho de ar-condicionado pode medir aí o nível da escola. E o estilo é uma escola de três pavimentos, com certeza é uma escola avançada, né? (113T, m, 41, ES, nse-m)

Porque são escola que dá um conforto ao aluno, a gente vê [...] que tem ar-condicionado, a gente vê que é ampla; o colégio é amplo. (38T, f, 23, EM, nse-b)

[...] é uma escola ... um lugar, assim, que o prédio tá vendo... que a criança teria assim uma área muito boa... pra se ter um lazer... aproveitar a criança ter um estudo melhor. Que pelo que a gente tá vendo aqui... a fotografia é um, é um, é um prédio lindo, espetacular... (52N, f, 51, EM, nse-b)

Porque é um prédio mais suntuoso, provavelmente deve ter ensino de informática. Deve estar numa era bem moderna. (10T, f, 41, ES, nse-m)

Eu acho que pela aparência do colégio... eu acho que funciona tudo melhor até pelo status do próprio colégio... porque hoje você... na porta do prédio você vê que uma escola dessa não pode ter um mau funcionamento. (6T, $\mathrm{m}, 42, \mathrm{EM})$

A compreensão, em síntese, é de que, havendo preocupação com o aspecto físico, também há com os demais itens:

[...] essa escola $\mathrm{n}^{\circ} 19$, né? ela me parece ser um... um colégio bem estruturado, né? Parece ser um colégio assim... 
pela aparência física, né? [...] Parece ser bem estruturado, né? E parece por conta disso ser... se há essa preocupação até com o físico, né?, me parece que deve haver também preocupação com... com a qualidade do ensino, né?, com a qualidade do... do... da formação também das pessoas do ponto de vista humanístico, também, e deve haver... deve haver bons professores, naturalmente, né?, bons recursos, né?, didáticos e recursos físicos mesmo e estrutura física, né? (11T, m, 47, ES, nse-m)

Porque pelo seu aspecto físico, pela forma, pela imponência do prédio fica subentendido que é uma boa escola. (117T, m, 45, ES, nse-m)

Porque ela impressiona pela sua estrutura física que aqui deveria ensinar melhor, porque a condição aparenta ser a melhor. (95T, m, 48, ES, nse-m)

[...] essas escolas outras que não é daqui de Teresina, eu acho que pela estrutura dá pra ver mais ou menos que têm um bom ensino... (42T, $\mathrm{f}, 25, \mathrm{ES}, \mathrm{nse}-\mathrm{m})$

Porque essas escolas mostram um poder aquisitivo elevado: salas com ar-condicionado, portão fechado, né? Me parece ser da melhor qualidade, né? E todo mundo quer dá o melhor para o seu filho, se puder. (15T, f, 32, EM, nse-b)

Porque é um colégio que realmente ele tem toda infraestrutura. Falando de infra-estrutura, tem espaço físico, tem... tem professores capacitados, tem... tem computador, tem toda o... o que o mundo moderno oferece, essa escola tem. E disciplina. São escolas que você pode botar seu filho e ficar tranqüilo em casa ou no trabalho e esperar que no final do ano o resultado é... da aprendizagem é excelente. (74T, m, 43, EM, nse-m)

Ou, ao contrário, onde não há preocupação com o aspecto físico também não há com os demais itens, como disse um dos entrevistados:

Pelo estado físico da escola aqui não pode ter um bom ensino... (114T, m, 46, ES, nse-m)
Desse modo, expressam a importância do prédio e da estrutura física como um todo na qualidade de uma escola, estabelecendo relação entre tamanho do prédio e nível de ensino: "quanto menor o prédio escolar, menor o nível de ensino atribuído à escola"; "quanto maior o prédio escolar, maior o nível de ensino atribuído à escola", como constatou Sales (2000, p. 243). Exceto as escolas públicas; essas, “[...] mesmo possuindo prédio com estrutura física superior a uma particular, obtinha, no julgamento, nível de aprendizagem dos alunos inferior ao da escola particular" (idem, p. 86) porque, explicam os entrevistados,

São escolas públicas. Apesar de serem grandes, mas o ensino não são elevados. (62T, f, 25, EM, nse-b)

Porque trata-se de escolas públicas e todas elas têm um núcleo comum voltado no... no que diz respeito à educação. São escolas de... de estrutura física muito boa, o que não necessariamente vai corresponder ao ensino oferecido, mas que são umas escolas aparentemente muito boas. Por isso, eu escolhi e também pertencentes, são escolas oficiais da rede pública, por isso que eu selecionei neste grupo. (78T, m, 34, ES, nse-m)

Mais uma vez, as apreciações davam lugar às recordações dos tempos tidos como auspiciosos, à constatação da decadência e ao desejo de que algo fosse feito para recuperar esse tempo perdido:

[...] mas esse Liceu... Liceu Piauiense - escola de n. 10 - foi uma escola tradicional que há muito tempo foi uma boa escola. Hoje, por... por o governo não mais incentivar o ensino público, né?, tá defasada em termos de ensino, né?, mas se a gente vê a parte física dela, é de boa qualidade e daria pra... se o governo incentivar o ensino público daria pra ser uma boa escola, uma escola modelo, né? O... a mesma resposta serve pra 12, eu encaixei por achar semelhante o prédio, eu acredito que se... vou partir do pressuposto que seja uma escola pública, que se o governo também incentivasse o ensino, daria pra ter.. ter um bom aprendizado pro aluno. (42T, f, 25, ES, nse-m) 
[...] Antigamente aqui em Natal, quando eu estudava, tinha duas escolas públicas que é a escola que os alunos não pagava, que tinha o ensino muito bom. Era o Atheneu e a Escola Industrial. E do Atheneu saiu grande advogado, saiu ministro, saiu grandes professores naquela época... $(31 \mathrm{~N}$, m, 56, EM, nse-m)

Porque é um colégio bom. É... pelo menos no passado foi. Agora a gente não sabe. (35N, f, 34, EM, nse-m)

A importância da estrutura física expõe, novamente, a associação entre custo e qualidade, desta feita para expressar: seletividade (quanto maior o preço, menor a quantidade procurada, vale dizer, acessível a poucos, pois poucos podem pagar), escassez (coisas caras têm menos oferta porque são produzidas em menor quantidade), distinção (o que existe para poucos e em número limitado confere ao possuidor destaque, distinção):

Porque de acordo com a arquitetura deles aqui, parece bem caro e colégio caro, geralmente, é bom. (100T, m, 30, ES, nse-b)

A esses elementos - prédio grande e suntuoso, estrutura física ampla, riqueza, alto custo - juntam a disciplina:

Porque são escolas mais estruturadas, né? Dá impressão de que... digamos os diretores... os... os... da escola têm mais rigidez com o ensino, quer dizer, é um ensino melhor. $(112 \mathrm{~N}, \mathrm{~m}, 61, \mathrm{EF}, \mathrm{nse}-\mathrm{b})$

Lá o ensino... além de ser um colégio de nome a zelar. Porque tem muito tempo que já existe em Natal. É um colégio que tem uma fama muito grande desde no... no seu início. Bons professores... é a rigidez muito grande no ensino. Lá a pessoa tem que aprender... (31N, m, 56, EF, nse-b)

Todos esses elementos denotam o desejo de ter algo mais que o necessário, ou seja, são elementos que compõem um estilo de vida, "um conjunto unitário de preferências distintivas" que dependem de toda a trajetória social, melhor dizendo, das posições ocupadas no espaço social. “Às diferentes posições no espaço social correspondem estilos de vida, sistemas de desvios diferenciais que são a retradução simbólica de diferenças objetivamente inscritas nas condições de existência" (Bourdieu, 1994, p. 82). Daí que, como se manifestou um dos entrevistados, disciplina e riqueza se complementam:

\footnotetext{
[...] E o Marista sempre dureza, né? A irmandade muito rica, não é verdade? Então, não agüenta muito abuso, não andou direito lá eles bota na porta da saída, não é verdade? Eu acho o seguinte: onde há hierarquia há respeito e há disciplina, e quando a hierarquia desaparece não há nada... o que há é esculhambação... Então, meu ponto de vista é esse. [...] O Marista...é o melhor mesmo. Na verdade nem tudo que você quer é esforço, porque você sabe que é somente estudar, né? Tem área de lazer, área esportiva... Você sabe que o esporte abre muito a mentalidade da pessoa, né? Então, o Marista tem tudo isso... No meu tempo tinha tudo, né? (66N, m, 67, EM, nse-b)
}

O professor é outro elemento que influencia na qualidade do ensino, às vezes como um complemento à estrutura física, às vezes como fator independente:

As escolas... as escolas do grupo 5 são escolas modernas, embora exista uma... a do n. 7 que pela sua modernidade devia funcionar com todo vapor, com uma estrutura moderna, com um corpo docente de alto nível para proporcionar um aprendizado, um estudo, né?, de alto... de nível razoável... (65T, m, 54, EM, nse-m)

Uma eu conheço e sei que o ensino lá não é essas coisas, a começar do seu professorado. Não é muito adaptado por... pelo menos é a n. 7, são professores que foram formados agora, que tão começando as suas atividades. Tão aprendendo ainda! Por isso eu acredito que não vai ser muita... não vai ter boa qualidade o ensino na 7. As outras, a 4 e a 11, é pelo seu aspecto físico que vai demonstrar, também, que as pessoas que ali tão trabalhando, não são qualificadas para dar um bom ensino. (70T, m, 67, EM, nse-m)

Porque pelo aspecto físico, ele parece que tem... é... local para que se estabilize realmente uma grande escola. 
Tá precisando apenas de um corpo docente preparado e realmente pronto para um trabalho maior... (70T, m, 67, EM, nse-m)

Porque são colégios totalmente precários, tanto num corpo físico quanto no... no corpo profissional, viu? Razão por essa que os professores não... não tão tendo nenhum incentivo [...], são mal remunerados, totalmente mal remunerados. (75T, m, 36, ES, nse-b)

Eles talvez iriam aí ilustrar a fachada, o tipo, vamos dizer, até a arquitetura do prédio; essa coisa que às vezes não é só o prédio por si que faz com que a pessoa aprenda, e $\operatorname{sim} o$ corpo docente $[\ldots]$ as pessoas que estiverem pensando que um edifício bonito, ele possa influenciar na educação da pessoa, está completamente enganado. O que vai influenciar na formação da pessoa é o corpo de professores. (119N, $\mathrm{m}, 61, \mathrm{EF}, \mathrm{nse}-\mathrm{m})$

Porque é um colégio de bons professores. A pessoa já cresce dentro do lado espiritual e religioso. Então a pessoa já sai com o futuro garantido. (89T, m, 36, ES, nse-b)

Porque é uma escola tradicional e religiosa, tem bons professores responsáveis, os alunos são muito cobrados em termos de estudo, oferece conforto e é bem localizado. (110T, f, 67, ES, nse-m)

Porque essas escolas, é... teriam péssimos professores, pela própria aparência da escola já se nota que... os professores são de baixo nível. (11T, m, 47, ES, nse-m)

Seja como elemento associado à estrutura física, seja como fator independente no processo educacional, aquele que tudo pode fazer, o professor é, para os entrevistados, o agente, aquele que age, que coloca as estruturas em funcionamento ou até mesmo consegue superar os limites impostos por elas. Contudo, não é qualquer professor; este precisa ser qualificado, ou seja, precisa ter condições para pôr em ação a estrutura, condições essas dadas pelos seus investimentos na profissão, especialmente os relativos à obtenção dos títulos escolares, e pelas aptidões necessárias para tal.
O professor também deve, conforme os entrevistados, obter retribuições materiais por sua ação, de que é emblema o salário, denotando que compreendem a docência como profissão.

A qualidade do ensino, portanto, depende: da classe social de quem frequienta a escola; de quem custeia essa escola; da experiência, representada pela tradição; da estrutura física; e do professor, que precisa ser bem remunerado e qualificado. Ocupa posição superior aquela que apresentar, em cada um dos fatores considerados, as características valorizadas. Assim, se uma escola é freqüentada por "ricos", custeada pelos alunos, possui larga experiência, um grande e belo prédio com salas confortáveis e espaços para atividades extraclasse e professores com formação superior e altos salários é uma escola com ensino de qualidade.

Ainda que essa possa ser a "regra geral", pode haver exceções. Uma no sentido de potencializar o resultado esperado: se a escola custeada por alunos for vinculada a alguma organização religiosa ou pelo menos apresentar algum símbolo de religiosidade (nome de santo, traços arquitetônicos similares a igrejas ou outros prédios religiosos...), a expectativa em relação à qualidade do ensino é maior. Outra em termos de redução dos efeitos desses fatores: se for uma escola pública, de pouco valerá seu grande e belo prédio, suas amplas salas de aula, suas quadras esportivas e espaços destinados a atividades recreativas e pedagógicas ou a qualificação de seus professores. Ela será sempre uma escola de pobre e, como tal, de ensino sem qualidade.

O que é, então, essa qualidade a que tanto se referem? Esse é o assunto do próximo item.

\section{A qualidade do ensino nas impressões da aparência}

O julgamento das escolas a partir das imagens dos prédios escolares que fazem os pais de estudantes do ensino fundamental e médio de Teresina (PI) e Natal (RN) permite compreender que o ensino de qualidade para esse conjunto de pessoas envolve: 
- instalações físicas, ou seja, prédio grande em que a arquitetura transmita "atributos valorizados como tradição e religiosidade em sua fachada" (Sales, 2000, p. 242), salas amplas, espaços físicos diversos destinados a atividades de lazer e pedagógicas, salas de multimeios, laboratórios, bibliotecas e conforto (climatização, carteiras anatômicas, entre outros), recursos didáticos modernos (quadros de acrílico, retroprojetores, data-show, por exemplo);

- disciplina rigorosa, ensino exigente e avançado;

- seletividade, isto é, caro, escasso e para poucos, numa expressão de difícil acesso;

- professores qualificados e bem remunerados.

A partir desses elementos, identifica-se que a representação social de ensino de qualidade dos entrevistados se constitui pelo binômio, aparentemente contraditório, "tradição e modernidade", pela palavra "seletividade" e pela expressão "professores qualificados e bem remunerados". Esses são, conforme a teoria do "núcleo central" (Abric, 2001), os elementos articuladores e organizadores que compõem a representação, sendo a base comum coletivamente partilhada das representações sociais. Segundo Domingos Sobrinho (1998, p. 125), “[...] é ele que permite a construção do consenso do grupo em torno do objeto representado e orienta as atitudes e ações em relação ao mesmo [...]", estando "diretamente vinculados", explica, "às condições históricas, sociológicas, psicológicas e culturais do grupo".

Esses elementos, ainda que permanentes, são continuamente ressignificados, adquirindo a conformação de cada momento histórico. Assim, o que hoje é novo amanhã poderá ser tradicional; o que é moderno poderá passar a ser obsoleto; o que é valorizado em um momento, no outro, poderá ser desvalorizado; o que é excelência poderá passar a ser incipiente. Por exemplo, os recursos didáticos antes eram os quadros de giz, hoje os quadros de acrílico; o retroprojetor deu lugar ao data-show, as transparências aos slides, e muitos outros. Ou o ensino de línguas estrangeiras, até bem pouco tempo apenas o inglês para as séries da segunda etapa do ensino fundamental; hoje, ao inglês junta-se o espanhol, às vezes desde a educação infantil. A substituição da aula magistral por outras formas de relação professor-aluno cujo emblema tem sido a valorização das chamadas abordagens construtivistas. O salário do professor, aspecto muitas vezes não só negligenciado, mas até omitido, uma vez que exigi-lo constituía quase uma blasfêmia, contrariando a dimensão vocacional e o caráter quase sagrado da docência.

A representação social de qualidade dos entrevistados expressa, portanto, os espaços sociais de que fazem parte e sua contemporaneidade, ou seja, o momento vivido pelos grupos sociais; ela não se dá no vazio social nem é produto da cognição. O que produz essas representações?

\section{Conclusão: a emersão do submerso nas apreciações}

O que está subjacente às apreciações dos pais de estudantes do ensino fundamental e médio e, conseqüentemente, às suas representações sociais de qualidade? O que se quer dizer com escola de rico, paga, religiosa, prédio grande e belo, com tradição e professores qualificados e bem pagos é escola com ensino de qualidade? Essas apreciações expressam um modo de organização do mundo social, “[...] não passam de alegorias que simulam a estrutura real das relações sociais" (Miceli, 1992, p. XIV). Assim, o modo como classificam as escolas e os fatores aos quais vinculam a qualidade do ensino faz parte do sistema simbólico que tem por função transfigurar e dissimular relações reais que estão em estreita ligação com o sistema social de que fazem parte.

Os sistemas simbólicos são instrumentos de conhecimento e de comunicação que têm o poder de construção da realidade, estabelecendo uma ordem gnoseológica (Bourdieu, 1989, p. 9) na qual as representações sociais, como "saber do senso comum ou ainda saber ingênuo, natural” (Jodelet, 2001, p. 22), ocupam posição primeira; são pontos de partida de que fazem parte. Essa autora destaca que são elemen- 
tos diversos - informativos, cognitivos, ideológicos, normativos, de crenças, valores, atitudes, opiniões, imagens etc. - organizados "sob a aparência de um saber que diz algo sobre o estado da realidade".

Nessas representações, por conseguinte, está subjacente a sociedade capitalista, com suas divisões de classe decorrentes da forma desigual de repartição do capital econômico e cultural e seus sistemas de dominação, bem como o "tipo humano" que esta produz, posto que os sistemas de classificação não apenas reproduzem a classificação dos homens e a organização social, como queria Durkheim (Durkheim \& Mauss, 1999, p. 403), mas também, como disse Bourdieu (1989, p. 11), são relações de poder cuja forma e conteúdo dependem dos agentes envolvidos, têm "[...] uma função política de instrumentos de imposição ou de legitimação da dominação de uma classe sobre outra"; são, na expressão desse autor, "um poder simbólico" exercido por agentes dotados das disposições e aptidões necessárias para tal, cujos investimentos os predispõem a isso e os fazem agir no sentido de reproduzir essas relações das quais são produto.

As representações sociais de qualidade do ensino dos sujeitos pesquisados, portanto, são não apenas formas de classificação do universo escolar como também expressão de relações de poder de uma classe sobre a outra, exercido por agentes cujas propriedades possibilitam definir um bem como legítimo e, como tal, elemento de distinção. Por conseguinte, conhecêlas - e, mais precisamente, as categorias sob as quais elas se assentam - é desvendar o que está em jogo na luta política pelo poder de conservar ou transformar o mundo social, conservando ou transformando as categorias de percepção desse mundo, posto que fornecem as analogias sob as quais se fundamentam as instituições sociais.

\section{Referências bibliográficas}

ABRIC, Jean Claude. O estudo experimental das representações sociais. In: JODELET, Denise (Org.). As representações sociais. Rio de Janeiro: EDUERJ, 2001. p. 155-172.
BOURDIEU, Pierre. O poder simbólico. Lisboa: Difel; Rio de Janeiro: Bertrand Brasil, 1989.

Gostos de classe e estilos de vida. In: ORTIZ, Renato

(Org.). Pierre Bourdieu/Sociologia. 2. ed. São Paulo: Ática, 1994. p. $82-121$.

BRASIL. MEC. Lei n. 10.172, de 24 de janeiro de 2001. Dispõe sobre o Plano Nacional de Educação. Brasília-DF. Disponível em: <http://www.mec.gov.br/>. Acesso em: 16 fev. 2004.

DOMINGOS SOBRINHO, M. Habitus e representações sociais: questões para o estudo de identidades coletivas. In: MOREIRA, Antônia S. Paredes; OLIVEIRA, Denize Cristina de (Orgs.). Estudos interdisciplinares de representação social. Goiânia: AB, 1998. p. 117-149.

DURKHEIM, Émile. As formas elementares da vida religiosa. São Paulo: Abril Cultural, 1978.

DURKHEIM, Émile; MAUSS, Marcel. Algumas formas primitivas de classificação. In: MAUSS, Marcel. Ensaios de sociologia. 2. ed. São Paulo: Perspectiva, 1999. p. 399-455.

EPENN - ENCONTRO DE PESQUISA EDUCACIONAL DO NORTE E NORDESTE, 17., 2005, Belém. Anais... Belém: UFPA, 2005.

FERRÃO, Maria Eugênia; FERNANDES, Cristiano. O efeitoescola e a mudança: dá para mudar? Evidências da investigação brasileira. Revista Electrónica Iberoamericana sobre Calidad, Eficacia y Cambio en Educación, Madrid, v. 1, n. 1, 2003. Disponível em: <http://www.ice.deusto.es/RINACE/reice/portada.htm>. Acesso em: 20 jan. 2005.

JODELET, Denise. Representações sociais: um domínio em expansão. In: (Org.). As representações sociais. Rio de Janeiro:

EDUERJ, 2001. p. 17-44.

MICELI, Sérgio. Introdução: a força do sentido. In: BOURDIEU, Pierre. A economia das trocas simbólicas. 3. ed. São Paulo: Perspectiva, 1992. p. VII-LXI.

MOSCOVICI, Serge. A representação social da psicanálise. Rio de Janeiro: Zahar Editores, 1978.

POLANYI, Karl. A grande transformação: as origens da nossa época. 2. ed. Rio de Janeiro: Campus, 2000.

ROCHA, Ruth. Quando a escola é de vidro. In: Este admirável mundo novo. Rio de Janeiro: Salamandra, 1986.

SÁ, Celso Pereira de. Representações sociais: o conceito e o estado atual da teoria. In: SPINK, Mary Jane p. (Org.). O conhecimento no cotidiano: as representações sociais na perspectiva da psicologia social. São Paulo: Brasiliense, 1995. p. 19-45. 
SALES, Luís Carlos. O valor simbólico do prédio escolar. Teresina: EDUFPI, 2000.

WEBER, Max. Conceitos sociológicos fundamentais. In:

Metodologia das ciências sociais. 2. ed. São Paulo: Cortez; Campinas: Editora da UNICAMP, 1995. p. 399-429.

LUÍS CARLOS SALES, doutor em educação pela Universidade Federal do Rio Grande do Norte (UFRN), é professor no Programa de Pós-Graduação em Educação da Universidade Federal do Piauí (UFPI). Publicações recentes: "Educação superior no Piauî" (In: RISTOFF, Dilvo; GIOLO, Jaime (Orgs.). Educação superior brasileira 1991-2004. Brasília: Instituto Nacional de Estudos e Pesquisas Educacionais Anísio Teixeira, 2006, v. 28); Educação: mediações simbólicas (em parceria com PASSOS, Guiomar de Oliveira (Orgs.), Teresina: EDUFPI, 2006). Pesquisa atual: "As representações sociais de escola de qualidade partilhadas por professores das escolas de Teresina mais bem posicionadas no ENEM", financiada pelo Conselho Nacional de Desenvolvimento Científico e Tecnológico (CNPq). E-mail: lwis2006@gmail.com
GUIOMAR DE OLIVEIRA PASSOS, doutora em sociologia pela Universidade de Brasília, é professora no mestrado em políticas públicas e no Departamento de Serviço Social da Universidade Federal do Piauí (UFPI). Publicações recentes: Educação: mediações simbólicas (em parceria com SALES, Luís Carlos (Orgs.), Teresina: EDUFPI, 2006); “A universidade como parte do jogo dos dominantes: relação entre ação do Estado e habitus" (In: ALBUQUERQUE, Luiz Botelho (Org.). Currículos contemporâneos: formação, diversidade, identidade e transição. Fortaleza: Editora da UFC, 2005. p. 211-229). Pesquisa atual: "Educação superior e reprodução das desigualdades sociais: estudo sobre o acesso à universidade pública”, financiada pelo Conselho Nacional de Desenvolvimento Científico e Tecnológico (CNPq), e "A qualidade da qualidade no público e no privado: os elementos empíricos das representações sociais", financiada pela Fundação de Apoio à Pesquisa do Estado do Piauí (FAPEPI). E-mail: guiomar. passos@uol.com.br; guiomar@ufpi.br

Recebido em agosto de 2007 Aprovado em dezembro de 2007 
Luís Carlos Sales e Guiomar de Oliveira Passos

\section{As aparências não enganam: as representações sociais de qualidade suscitadas pelos prédios escolares Neste trabalho são investigadas as representações sociais presentes nas apreciações de escolas feitas por pais entrevistados por Sales (2000) em pesquisa sobre "o valor simbólico do prédio escolar". Objetiva-se identificar elementos para um conceito de ensino}

de qualidade, buscando o que está subjacente a essas apreciações. O material explorado consiste num corpus formado por depoimentos de pais de estudantes do ensino fundamental e médio de Teresina (PI) e Natal (RN), destacando os critérios de julgamento envolvidos na classificação das escolas, ou seja, os princípios norteadores da ação. Os depoimentos mostraram que ensino de qualidade envolve instalações físicas, disciplina rigorosa, ensino exigente e avançado; seletividade e professores qualificados e bem remunerados, sendo parte do sistema simbólico que tem por função transfigurar e dissimular relações reais que estão em estreita ligação com o sistema social de que fazem parte.

Palavras-chave: representações sociais; ensino de qualidade; escola de qualidade; educação

Appearances do not deceive: social representations of quality provoked by school buildings

This paper investigates the social representations present in the appreciation of schools by parents who were interviewed by Sales (2000) during a research on "the symbolic value of the school building". The aim of this work is to identify elements which contribute to build the concept of quality teaching, searching for what is subjacent to these appreciations. The material explored consists of a corpus made up by statements of parents with children at primary and secondary school in Teresina, the state capital of Piaui and Natal, capital of Rio Grande do Norte, highlighting the judgment criteria involved in the classification of schools, that is, the guiding principles of action. The statements showed that quality teaching involves the physical features of the building, severe discipline, strict and advanced teaching; selectivity and well paid and qualified teachers, all of them being part of the symbolic system whose function is to transfigure and dissemble real relationships that are linked to the social system of which they are part.

Key words: social representations; quality teaching; school of quality; education

Las apariencias no engañan: las representaciones sociales de calidad suscitadas por los edificios escolares En este trabajo son investigadas las representaciones sociales presentes en las apreciaciones de escuelas hechas por padres entrevistados por Sales (2000) en pesquisa sobre "el valor simbólico del edificio escolar”. Tiene como objetivo identificar elementos para un concepto de enseñanza de calidad, buscando lo que está subyacente en esas apreciaciones. El material averiguado consiste en un corpus formado por declaraciones de padres de estudiantes de enseñanza primaria y secundaria de Teresina (PI) y Natal (RN), destacando los criterios del juicio involucrados en la clasificación de las escuelas, o sea, los principios indicadores de la acción. Las declaraciones mostraron que la enseñanza de calidad envuelve instalaciones físicas, disciplina rigurosa, Enseñanza exigente y avanzada; selección y profesores calificados y bien pagos, siendo parte del sistema simbólico que tiene por función transfigurar y encubrir relaciones reales que están en estrecha relación con el sistema social del que forman parte.

Palabras clave: representaciones sociales; enseñanza de calidad; escuela de calidad; educación 